\title{
FIELD ORIENTATION CONTROL OF STEPPER MOTORS
}

\author{
Samia M. Mahmoud, M. Z. Elsherif, Hassan A. Mansour, and Emad S. Abdel-Aliem \\ Electrical Engineering Department, Faculty of Engineering, \\ Benha University, Egypt
}

\begin{abstract}
Step motors are receiving wide attention in industrial applications which require high performance. They are used in open loop control of position and translation motion but have poor performance. This paper discusses open loop control using field orientation of step motors to improve its dynamic performance. A simplified mathematical model of two phase variable reluctance (VR) stepper motor is introduced. Advance turn-on and advance turn-off is presented to obtain the optimal control angle in order to decrease phase current rise time, produce maximum torque per ampere, elimination of negative torque region, reducing motor losses, and increasing motor efficiency. A drive circuit for two phase VR step motor is implemented. The simulation results of stator current are compared to the experimental results.

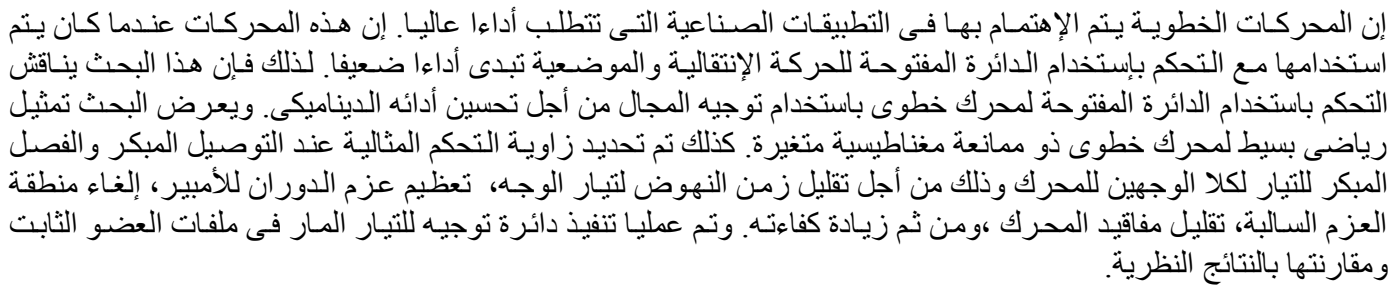

Keywords: FOC; VR step motor; Advance turn-on; Advance turn-off and Torque per ampere.

\section{List of Symbols}

$i_{A} \quad$ The instantaneous current in phase $A, \mathrm{~A}$.

$i_{B} \quad$ The instantaneous current in phase $B, \mathrm{~A}$.

$I_{O N} \& I_{O F F}$ The phase current during turn on $\&$ turn off period, A

$L_{0} \quad$ The average phase inductance, $\mathrm{H}$.

$L_{l} \quad$ The amplitude of inductance variation with rotor position, $\mathrm{H}$.

$L_{A}(\theta) \& L_{B}(\theta)$ The inductance of phase $A \& B$ as function of rotor position, $\mathrm{H}$.

$N_{R} \quad$ The total number of rotor teeth.

$R \quad$ The phase winding resistance, $\Omega$.

$T_{A} \& T_{B} \quad$ The torque generated in phase $A \&$ $B, \mathrm{Nm}$.

$T_{e} \quad$ The total electromagnetic torque, $\mathrm{Nm}$.

$t_{\text {ON }} \& t_{O F F} \quad$ The turn on \& turn off time, s.

$U \quad$ The rated supply voltage, $\mathrm{V}$.

$\theta \quad$ The step angle or rotor position, ${ }^{\circ}$.

$\theta_{r} \quad$ The rated step angle of stepper motor, ${ }^{\circ}$.

$P \quad$ The total number of motor phases.

$N \quad$ The motor speed, $\mathrm{rpm}$.

\section{INTRODUCTION}

The step, stepper, or stepping motors are attractive because they can be controlled by computers or microcontrollers. The output shaft rotates in a series of discrete angular intervals or steps. When a definite number of pulses have been supplied, the shaft will have turned through a known angle, and this makes the motor ideally suited for open loop position control [1,2]. Types of stepper motor are variable reluctance, permanent magnet and hybrid [3]. The most commonly used types are variable reluctance and hybrid [4]. Stepper motors are designed to allow both rotation and translation motions [5]. Stepping motors are used where position control must be sharp and fast such as in robotics, banking systems, drilling machines, machine tools, printers, and scanners due to lack of contact aging, less weight, small power, absence of rotor windings, and external rotor excitation $[6,7]$.

It is known that the field orientation control (FOC) has huge computational requirements. But, this paper introduces FOC of simple mathematical operations using two techniques which they are advance turn-on and advance turn-off. An optimal control angles is deduced in order to eliminate negative torque region, produce maximum torque per ampere, and increasing motor efficiency. 


\section{MODELING OF STEPPER MOTOR}

According to the electromagnetic theory, the shaft of the stepper motor will turn a precise distance when a pulse is received from the driver. For example, a two phase VR stepper motor has a stator consists of six poles and rotor consists of four poles as shown in Fig.1. The motor will move 12 steps for making one complete revolution according to the relation $\left(360^{\circ} / N_{R} P\right)$. This means that the rotor has 12 possible detent positions. When the rotor is in a detent position, it will have enough magnetic force to keep the shaft from moving to the next position. By changing the current flow to the next stator winding, the rotor will only move one step of $30^{\circ}$. The motor will make one quarter revolution through the following steps:
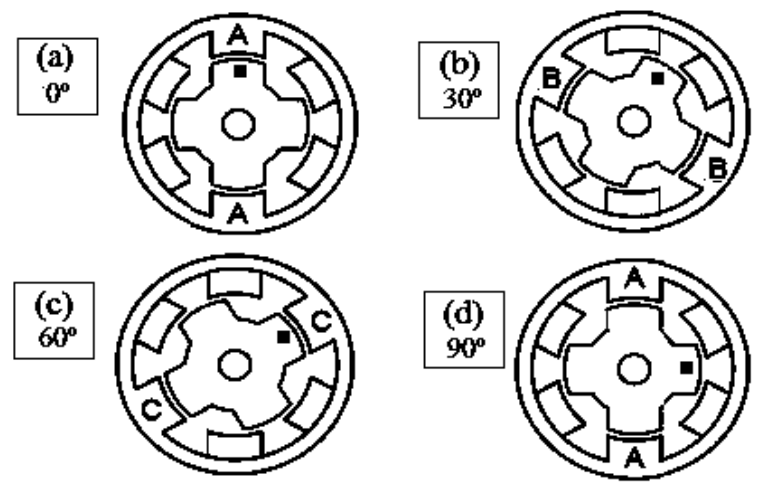

Fig.1 A one quarter revolution of a 2-phase VR step motor

Fig.1 (a) phase $A$ is energized

Fig.1 (b) phase $B$ is energized

Fig.1 (c) phase $C$ is energized

Fig.1 (d) phase $A$ is energized

When a constant current is passed through one phase, the motor generates a torque. This torque is typically a sinusoidal function of rotor displacement from the detent position [8]. When the stator and rotor teeth are fully aligned the circuit reluctance is minimized and the magnetic flux is at its maximum value [1].

Precise mathematical modeling of variable reluctance step motor type requires knowledge of both the geometry of the machine and of the ferromagnetic material characteristics. These requirements and assumptions are made to simplify.

Assumption 1: The ferromagnetic material does not saturate.

Assumption 2: The inductance for each phase varies as a sinusoidal around the circumference of the air gap.

The inductances and current equations for two phases (phase $A$ and $B$ ) variable reluctance stepper motor are:

$L_{A}(\theta)=L_{0}+L_{1} \cos \left(N_{R} \theta\right)$

$$
\begin{aligned}
& L_{B}(\theta)=L_{0}+L_{1} \cos \left(N_{R} \theta+\theta_{r}\right) \\
& I_{\text {ON }}=\left(\frac{U}{R}\right)\left(1-e^{-\left(\frac{\boldsymbol{t}_{\text {ON }}}{\tau}\right)}\right) \\
& I_{\text {OFF }}=\left(\frac{U}{R}\right)\left(\boldsymbol{e}^{-\left(\frac{\boldsymbol{t}_{\text {OFF }}}{\tau}\right)}\right)
\end{aligned}
$$

Where, $\tau$ is the time constant; $L / R, s$.

Using conservation of energy, the generated torque is:

$$
\begin{aligned}
T_{A} & =-\frac{L_{1} N_{R}}{2} i_{A}{ }^{2} \sin \left(N_{R} \theta\right) \\
T_{B} & =-\frac{L_{1} N_{R}}{2} i_{B}{ }^{2} \sin \left(N_{R} \theta+\theta_{r}\right) \\
T_{e} & =T_{A}+T_{B} \\
& =-\frac{L_{1} N_{R}}{2}\left[i_{A}{ }^{2} \sin \left(N_{R} \theta\right)+i_{B}{ }^{2} \sin \left(N_{R} \theta+\theta_{r}\right)\right]
\end{aligned}
$$

The output and input power; $P_{o} \& P_{i}$ relations can be written as:

$P_{o}=T_{e}\left(\frac{2 \pi N}{60}\right)$

$P_{i}=U I_{O N}$

\section{THE PROPOSED CONTROL CIRCUIT}

FOC will result in smooth, precise and responsive speed control when the load changes $[9,11]$. Optimized efficiency even during transient operation, less power consumption, less noise and excellent torque dynamics is introduced.

The open loop drive scheme for two phase VR stepper motor that is shown in Fig.2 has low cost and simple construction. The supply voltage $220 \mathrm{~V}_{\mathrm{ac}}$ (rms) is converted into 12 to $24 \mathrm{~V}$ via AC/DC converter to be suited for stepper motor driving.

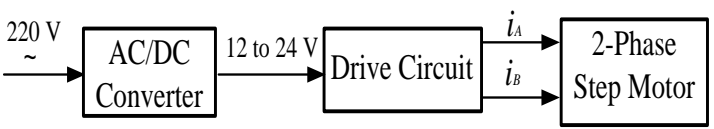

Fig.2 The proposed step motor open loop drive

The driver contains the switching circuits, which supply the motor. The motor output is the angular position of the rotor, while the input is digital signals. In this scheme there is no feedback and therefore the motor responds to each excitation change.

\section{SIMULATION RESULTS}

A small two phase VR stepping motor (phase $A$ and $B$ ) was used with $N_{\mathrm{R}}=50$ rotor tooth, source voltage $12 \mathrm{~V}$, phase resistance $R=25 \Omega$, step angle $3.6^{\circ}$, average phase inductance $L_{0}=0.027 \mathrm{H}$, amplitude of the inductance variation with rotor 
position $L_{l}=0.0135 \mathrm{H}$ and motor speed $N=100$ rpm.

The methods of FOC control at full stepping such as advance turn-on and turn-off will be recognized and their dependence on machine parameters and the requirement to maximize torque will be discussed. Also, the half stepping mode of operation is used here.

\section{A. Motor Performance Characteristics with FOC (Advance Turn-on)}

Improvement of the stepper motor characteristics is presented by the control of conduction angle of phase current. The advance turnon angle is measured from the unaligned position of motor phase. The advance turn-on angle $\alpha$ equals $0^{\circ}, 0.5^{\circ}, 1^{\circ}$ and $1.5^{\circ}$ (where $\alpha$ is the turn on angle that measured from the unaligned position) will be presented to allow phase currents to be supplied before generating undesired negative torque.

The motor phases current versus rotor angle is shown in Fig.3. For each phase an advance turn-on angle $\alpha$ equals $0^{\circ}, 0.5^{\circ}, 1^{\circ}$ and $1.5^{\circ}$ is considered.

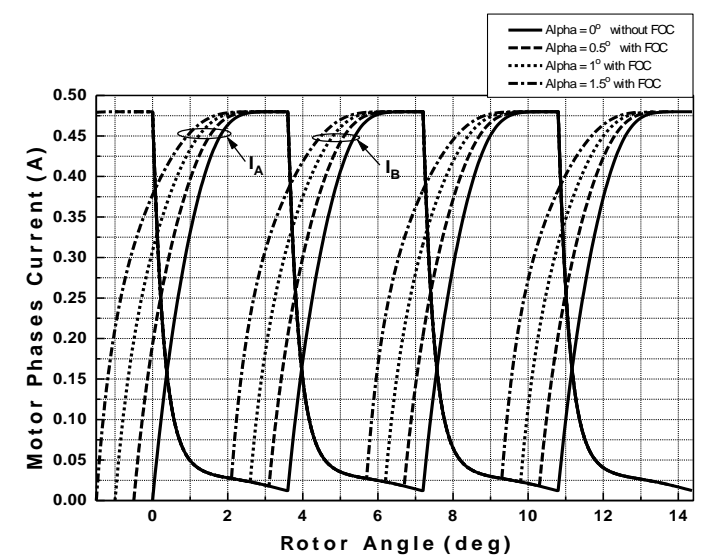

Fig.3 Motor phases current versus rotor angle during four step angles

The motor total torque versus rotor angle during advance turn-on angle $\alpha=0^{\circ}, 0.5^{\circ}, 1^{\circ}$ and $1.5^{\circ}$ is shown in Fig.4. As the angle of advance increases, the torque pulsation of the motor increases. If the current is exponentially increases while the rotor and stator teeth are approaching alignment position then $(d L / d \theta)>0$ and the torque is positive, signifying motoring operation. Alternatively, if the current is exponentially decreases when the teeth are being pulled away from alignment position then $(d L / d \theta)<0$ and the torque is negative corresponding to generating (braking) operation. It is clear from Fig.4 that the total torque is increased and the negative torque region is eliminated as the advance turn-on angle increased.

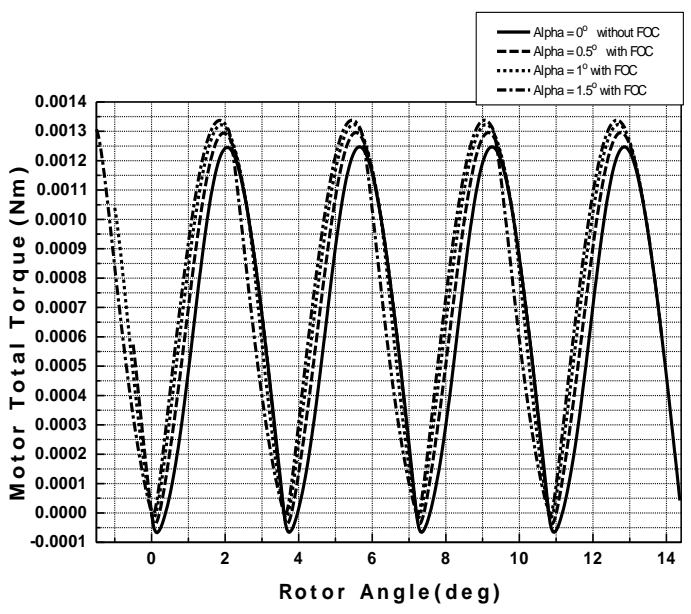

Fig.4 Motor total torque versus rotor angle during four step angles

The motor output power variation with rotor angle is shown in Fig.5 at advance turn-on angle $\alpha=0^{\circ}, 0.5^{\circ}, 1^{\circ}$ and $1.5^{\circ}$. The output power increases when the advance turn-on angle increases. Maximum output power is obtained at advance turn-on angle $\alpha=1.185^{\circ}$ as will be concluded after in the average characteristics. Also, The negative output power regions are eliminated as the turn-on angle increases.

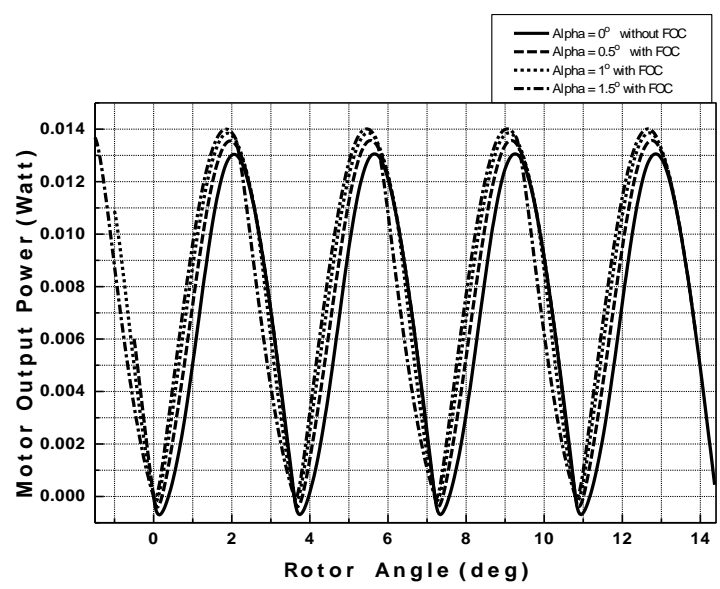

Fig.5 Motor output power versus rotor angle during four step angles

\section{B. Motor Performance Characteristics with FOC (Advance Turn-off)}

For improving the stepper motor operation; FOC is applied through an advance turn-off of the phases current. Therefore, it is becomes necessary to turn off the currents before they reach the completely aligned position. Fig.6 shows the motor phases current versus rotor angle at an advance turn-off angle $\beta=0^{\circ}, 0.25^{\circ}, 0.5^{\circ}, 0.75^{\circ}$ and $1^{\circ}$ (where $\beta$ is the turn off angle that measured from the aligned position). For early switching off, as $\beta$ increases the stator current is not possible to maintain a constant peak current and rapidly decreases to zero value. 


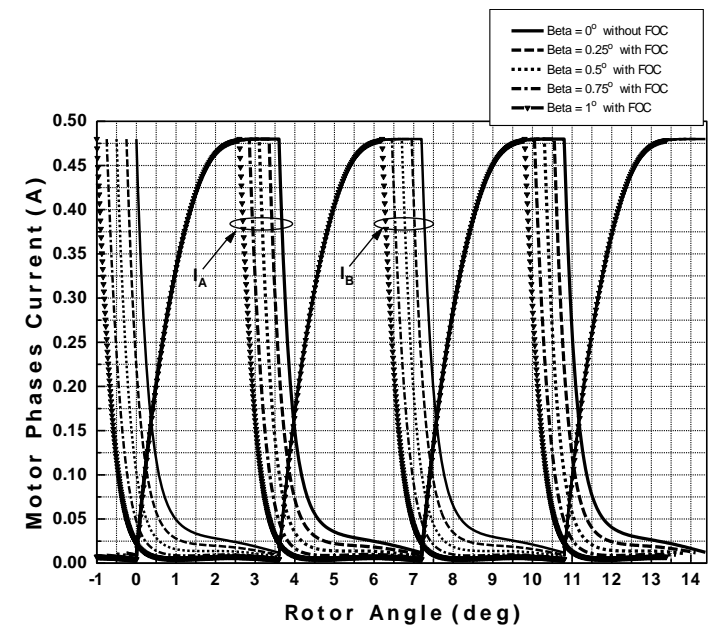

Fig.6 Motor phases current versus rotor angle during four step angles

The motor total torque versus rotor angle is shown in Fig.7. The negative torque region is eliminated with increasing the turn-off angle. The torque magnitude is controlled by varying the magnitude of the phase currents. The direction of the torque is controlled by varying the placement of the current pulses with respect to rotor position. A good starting torque is produced as advance turn-off angle is increased.

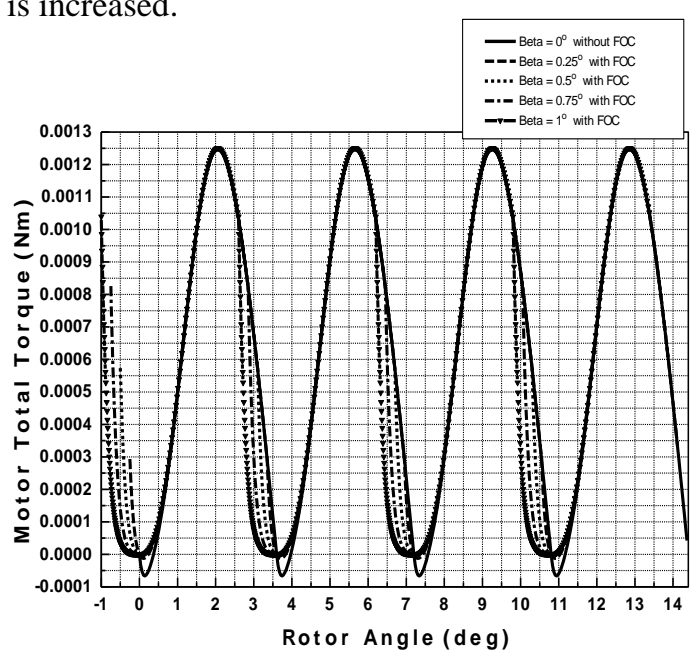

Fig.7 Motor total torque versus rotor angle during four step angles

Figure 8 shows the motor output power versus rotor angle. Advance turn-off technique eliminates the negative region in the motor output power. The negative output power region is eliminated with increasing the advance turn-off angle.

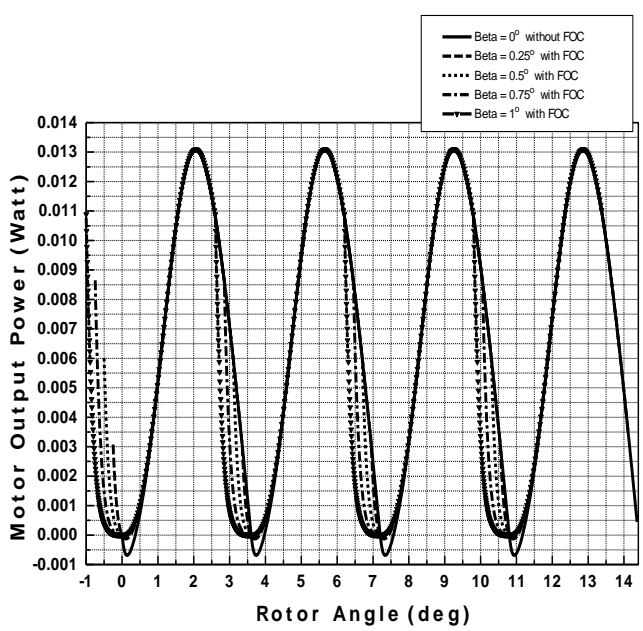

Fig.8 Motor output power versus rotor angle during four step angles

Figure 9 shows the motor input versus rotor angle. The required input power is decreased with increasing the advance turn-off angle. As result of increasing output power and decreasing input power; efficiency is increased.

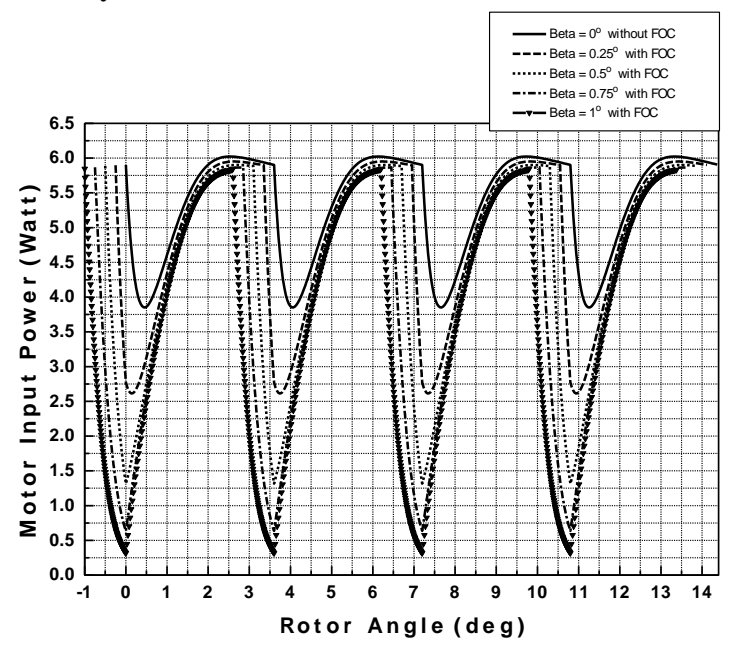

Fig.9 Motor input power versus rotor angle during four step angles

\section{Motor Average Characteristics as Function of Turn on Angle}

The average ch/s will be obtained at different speeds. The motor average $\mathrm{ch} / \mathrm{s}$ will be obtained as function of advance turn-on angle $\alpha$ which changes from $0^{\circ}$ to $3^{\circ}$. Then, the maximum average value of the motor ch/s will be obtained at the best turn-on angle.

Figure 10 shows the motor phases average current versus advance angle at different speeds. The average current increases with increasing the advanced turn-on angle $\alpha$ at speed $100 \mathrm{rpm}$ but decreases with speeds above $200 \mathrm{rpm}$. 


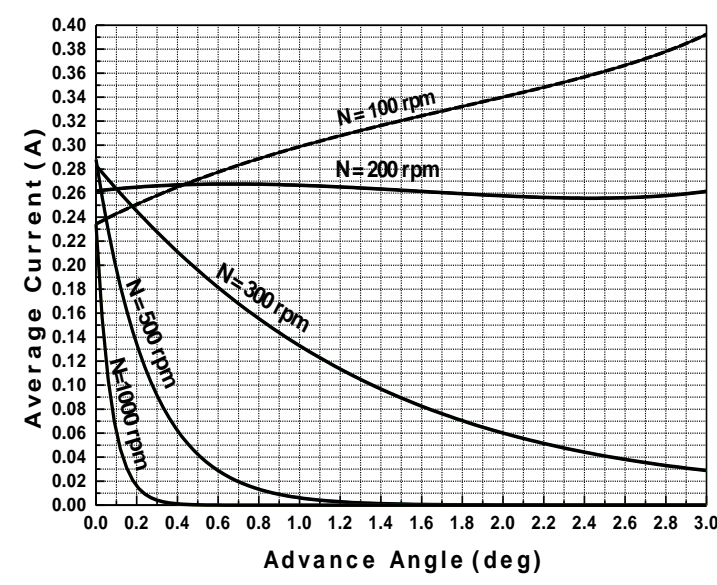

Fig. 10 Motor phases average current versus advance turn-on angle at different speeds

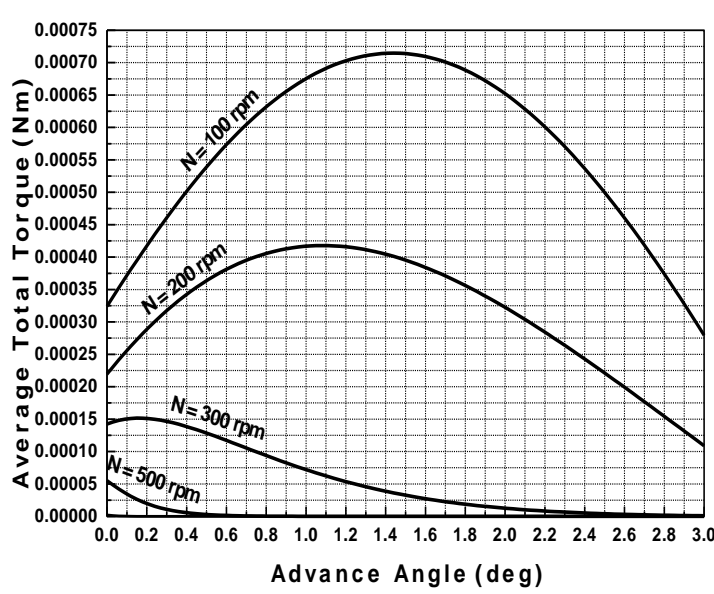

Fig.11 Average total torque versus advance turn-on angle at different speeds

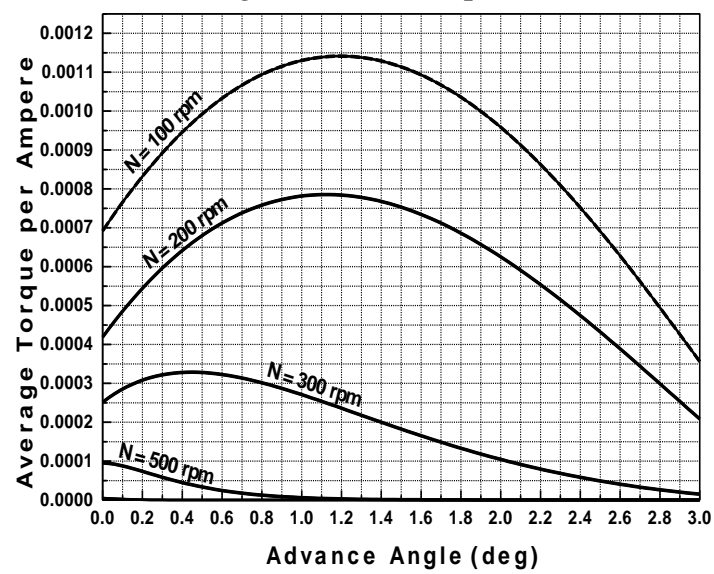

Fig.12 Average torque per ampere versus advance turn-on angle at different speeds

The average total torque versus advance angle is shown in Fig.11. Maximum value of the torque differences from speed to the other according to the optimal control angle. Fig.12 shows the motor average torque per ampere versus advance turn-on angle.

\section{Motor Average Characteristics as Function of Turn off Angle}

Fig.13 shows the motor phases average current versus advance angle at different speeds. The average current decreases as the advanced turn-off angle of the stator current increases.

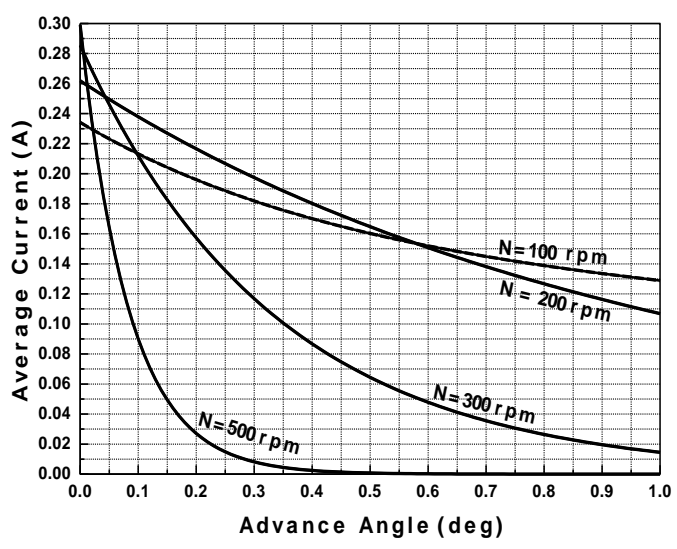

Fig.13 Motor phases average current versus advance turn-off angle at different speeds

The average total torque versus advance angle is shown in Fig.14. Maximum torque value differences from speed to the other. Average torque increases as turn-off angle increases at lower speeds.

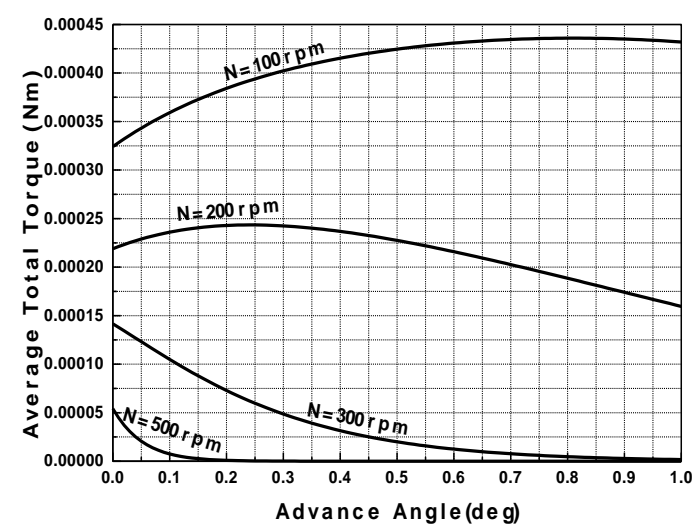

Fig.14 Average total torque versus advance turn-off angle at different speeds

Figure 15 shows the motor average torque per ampere versus advance angle. The torque per ampere increases as advance turn-off angle increases at lower speeds. As result of increasing the advance angle; the stator current not maintained at rated value and the motor losses will be decreased.

\section{E. Motor Average Characteristics as Function of motor Speed}

The motor phases maximum average torque per ampere (for phase 4.1 and 4.2) at advance turn-on as function of motor speed is shown in Fig.16. As the motor speed increases; the motor phases maximum average torque per ampere decreases. Maximum average torque per ampere is obtained at lower speed. 
The motor phases maximum average torque per ampere (phase A and B) at advance turn-off as function of motor speed is shown in Fig.17. As the motor speed increases the motor phases maximum average torque per ampere decreases.

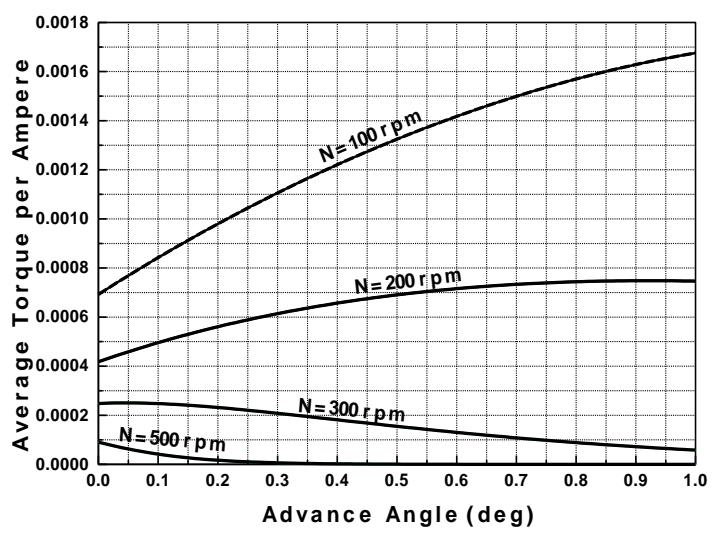

Fig.15 Average torque per ampere versus advance turn-off angle at different speeds

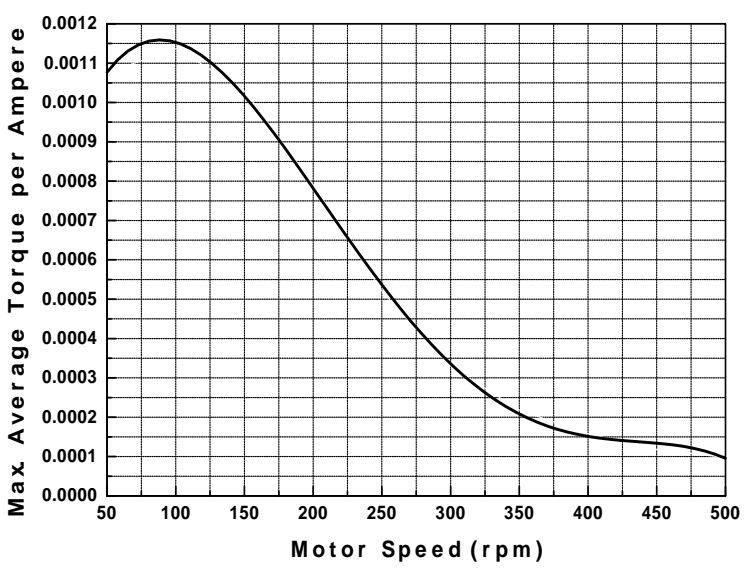

Fig.16 Maximum average torque per ampere versus motor speed (advance turn-on)

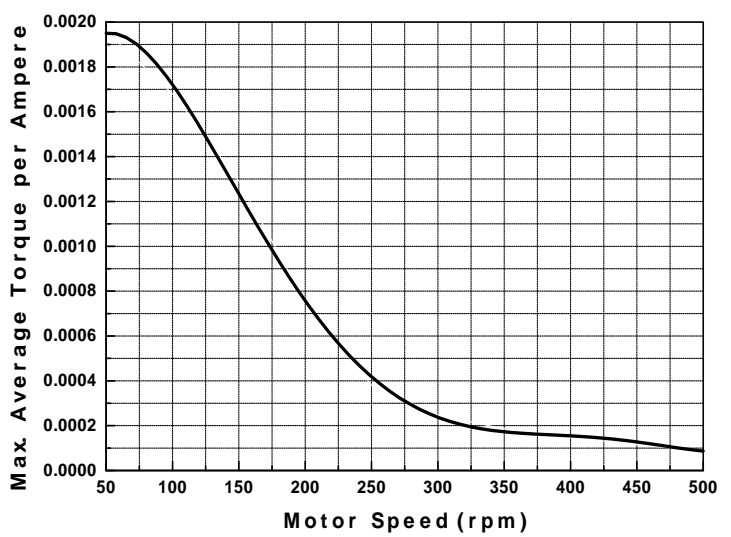

Fig.17 Maximum average torque per ampere versus motor speed (advance turn-off)

\section{EXPERIMENTAL RESULTS}

The hardware configuration of the experimental setup of open loop drive of step motor and the software organization is introduced here. A schematic diagram of the experimental connection

is shown in Fig.18. An experimental setup of stepper motor driver is shown in Fig. 19.

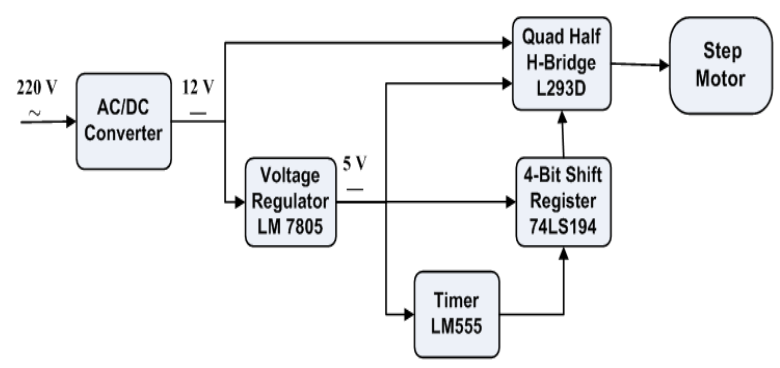

Fig.18 A brief schematic diagram of experimental connections

The experimental setup is simple and cheap. It is a stand alone bipolar stepper motor driver using parts that are available from many sources. The driver is designed for medium and low speed applications with motors that draw up to $1.0 \mathrm{~A} /$ phase. This driver provides only basic control functions such as forward, reverse, and stops.

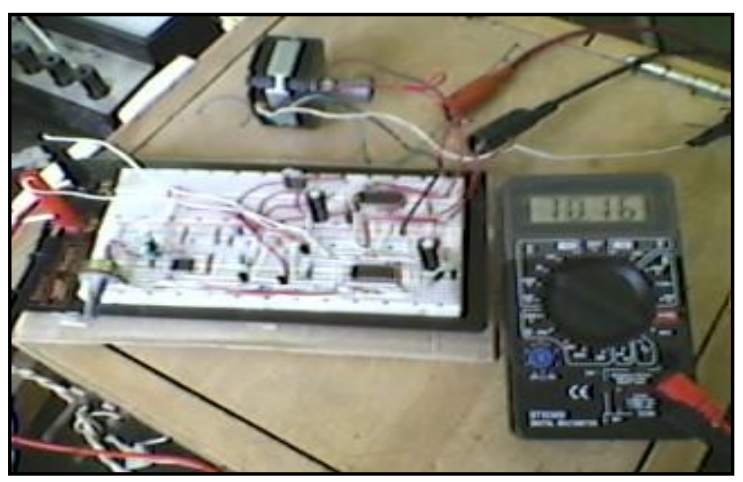

Fig.19 A photograph of the experimental setup of stepper motor driver

The oscillograms are taken when the stepper motor is operated at $10 \mathrm{~V}$. Fig.20 through Fig.23 shows the voltage and the current of one phase when the motor rotates at supply voltage of $10 \mathrm{~V}$ that applied from the converter at different frequencies. The output phase voltage is a square wave of 10 V/div (the upper trace in each photo). The operating time is $20 \mathrm{~ms} / \mathrm{div}$. The phase current of scale $0.2 \mathrm{~A} /$ div. (the lower trace in each photo) is exponentially increases with the positive phase voltage but is exponentially decreases with the negative phase voltage. 


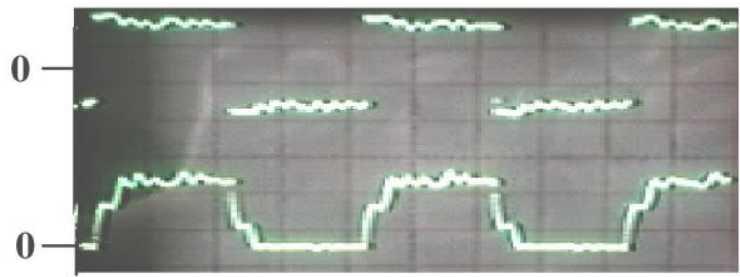

Fig.20 Stator voltage \& Stator current

Horizontal: Time $20 \mathrm{~ms} / \mathrm{div} \&$ Freq. $25 \mathrm{step} / \mathrm{s}$

Vertical: Upper Trace (Stator voltage) $10 \mathrm{~V} / \mathrm{div}$ Lower Trace (Stator current) $0.2 \mathrm{~A} / \mathrm{div}$

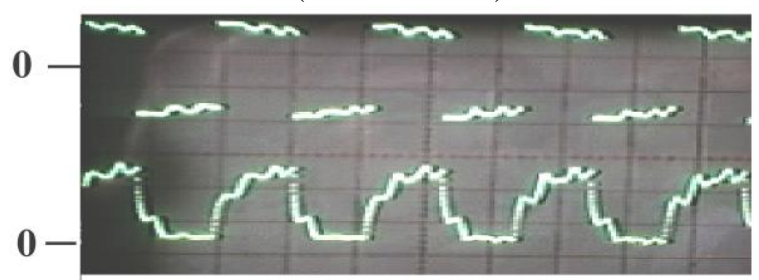

Fig.21 Stator voltage \& Stator current

Horizontal: Time $20 \mathrm{~ms} / \mathrm{div} \&$ Freq. $43 \mathrm{step} / \mathrm{s}$.

Vertical: Upper Trace (Stator voltage) $10 \mathrm{~V} / \mathrm{div}$ Lower Trace (Stator current) $0.2 \mathrm{~A} / \mathrm{div}$

The current waveform for one phase is exponentially increases with the positive phase voltage but is exponentially decreases with no applied phase voltage as shown in Fig.20 through Fig.23. These waveforms are similar to the theoritical results shown in Fig. 3 and Fig.6 for phase A.

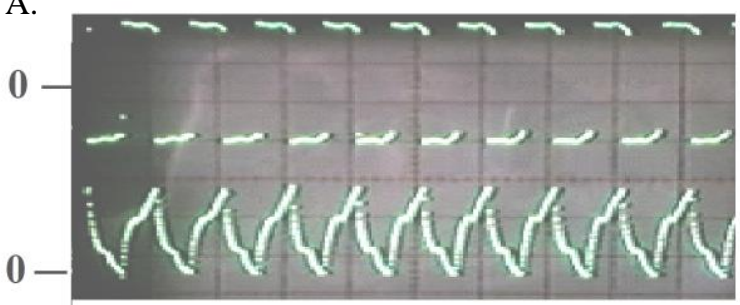

Fig.22 Stator voltage \& Stator current

Horizontal: Time $20 \mathrm{~ms} / \mathrm{div} \&$ Freq. $100 \mathrm{step} / \mathrm{s}$.

Vertical: Upper Trace (Stator voltage) $10 \mathrm{~V} / \mathrm{div}$

Lower Trace (Stator current) $0.2 \mathrm{~A} / \mathrm{div}$

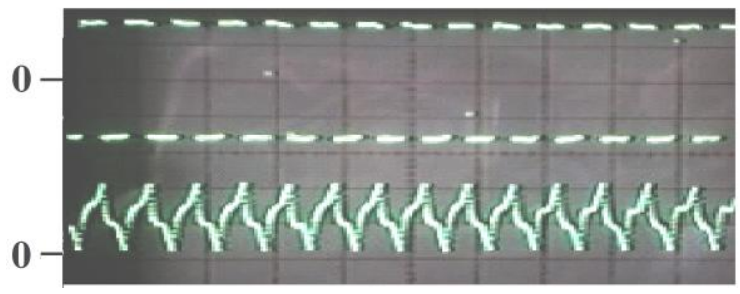

Fig.23 Stator voltage \& Stator current

Horizontal: Time $20 \mathrm{~ms} / \mathrm{div} \&$ Freq. $145 \mathrm{step} / \mathrm{s}$.

Vertical: Upper Trace (Stator voltage) $10 \mathrm{~V} / \mathrm{div}$

Lower Trace (Stator current) $0.2 \mathrm{~A} / \mathrm{div}$

\section{CONCLUSIONS}

Although FOC has huge computational requirements, but this paper introduces FOC of simple mathematical operations using two techniques advance turn-on and advance turn-off.
An optimal control angle is deduced to eliminate the negative region of torque and output power for increasing motor efficiency. By using advance turn-off, the phase current is switched off before full alignment instead of applying negative voltage that reduces motor average torque. Maximum torque per ampere can be obtained at certain speed and at certain advance angle.

Increase output power, decrease input power, and increase efficiency is achieved by advance turn-off. For stepper motor applications, maximum value of torque per ampere is obtained at different speeds.

\section{Acknowledgment}

Many thanks to Prof. Dr. Fathy A. Abdel-Kader; professor at faculty of engineering, Minoufiya University for his invaluable helps. Deepest gratitude to him for encouragement and for the valuable comments.

\section{REFERENCES}

[1] P.P. Acarnley, "Stepping motors: a guide to modern theory and practice", Peter Peregrinus Ltd., 1982.

[2] Austin Hughes, "Electric Motors and Drives: Fundamentals, Types and Applications", Third edition 2006.

[3] B. C. Kuo, "Incremental Motion Control, Step Motors and Control Systems", Champaign, IL: SRL Publishing, 1979.

[4] P.C. Sen, "Principles of Electric Machines and Power Electronics", Second Edition, John Wiley \& Sons, USA, 1997.

[5] Petar et al., "Microcomputer Implementation of Optimal Algorithms for Closed-Loop Control of Hybrid Stepper Motor Drives", IEEE Transactions on Industrial Electronics, Vol. 47, No. 6, December 2000.

[6] S. Bifaretti et al., "Global Learning Position Controls for Permanent-Magnet Step Motors", IEEE Transactions on Industrial Electronics, Vol. 58, No. 10, October 2011.

[7] A. Bellini, C. Concari, G. Franceschini, and A. Toscani, "Mixed-Mode PWM for High Performance Stepping Motors", IEEE Transactions on Industrial Electronics, Vol. 54, No. 6, December 2007.

[8] Saikiran Gumma, "A Radial Basis Funcion Neuro Controller For Permenent Magnet Stepper Motor", Master of Science in Electrical Engineering at the Cleveland State University, August, 2004.

[9] Harris, M. R., Andjargholi, V., Lawrenson, P. J., Hughes, A., and Ertan, "Unifying approach to the static torque of stepping motor structures", Proc. IEE, 122, No. 8, 1977.

[10] Singh et al., "Accuracy considerations in step motor systems", Proceedings of the eighth annual symposium on Incremental motion control systems and devices, University of Illinois, 1978.

[11]F. Blaschke, "The principle of Field Orientation Applied to the New Transvector Closed-Loop Control System for Rotating Field Machines", Siemens-Rev., vol. 39, pp. 217-220, 1972. 